\title{
Article
}

\section{Occupational lung disease: the need for a global surveillance system}

\author{
Asananti, Kaveh, Al Jassasi, Shiboun Hamed, Sherafat, Alireza and \\ Ferris, Mark \\ Available at https://clok.uclan.ac.uk/32594/ \\ Asananti, Kaveh, Al Jassasi, Shiboun Hamed, Sherafat, Alireza and Ferris, Mark \\ (2020) Occupational lung disease: the need for a global surveillance system. \\ Occupational and Environmental Medicine, 77 (7). pp. 506-507. ISSN 1351- \\ 0711
}

It is advisable to refer to the publisher's version if you intend to cite from the work. http://dx.doi.org/10.1136/oemed-2019-106323

For more information about UCLan's research in this area go to http://www.uclan.ac.uk/researchgroups/ and search for <name of research Group>.

For information about Research generally at UCLan please go to http://www.uclan.ac.uk/research/

All outputs in CLoK are protected by Intellectual Property Rights law, including Copyright law. Copyright, IPR and Moral Rights for the works on this site are retained by the individual authors and/or other copyright owners. Terms and conditions for use of this material are defined in the policies page.

\section{CLoK}

Central Lancashire online Knowledge www.clok.uclan.ac.uk

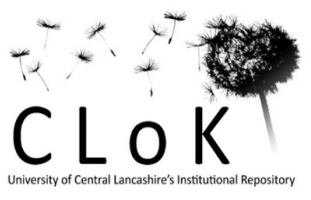


Title:

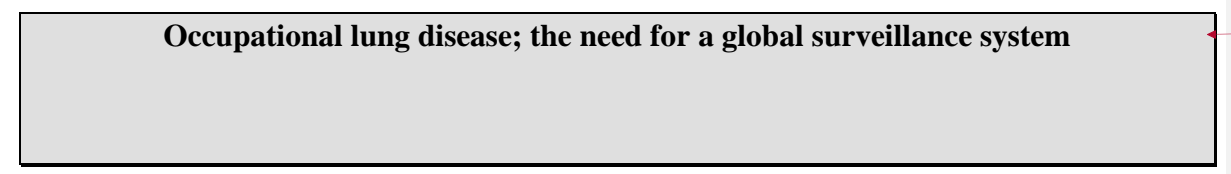

Formatted: Line spacing: Double

SHORT TITLE: GLOAL SWORD SCHEME

Paper (Letter to Editor) to be submitted to:

By:

Kaveh Asanati $^{(1)}$; Shiboun Hamed AL Jassasi ${ }^{(2)}$; Alireza Sherafat ${ }^{(3)}$; Mark Ferris $^{(4)}$

1. Department of Pharmacology, Therapeutics and Toxicology, School of Medicine,

Cardiff University, Heath Park, Cardiff CF14 4XN, UK

2. Occupational Health, Petroleum Development Oman, SULTANTE OF

OMAN/Ibri/AlAred, PoB: 961 POC:511

3. School of Medicine, University of Central Lancashire, 135A Adelphi St, Preston PR1 7BH, UK 
4. Occupational Health, Cambridge University Hospitals NHS Foundation Trust,

Box 172 ,Cambridge Biomedical Campus

Hills Road

Cambridge, CB2 0QQ UK

\section{Corresponding author:}

Dr Kaveh Asanati

School of Medicine

Cardiff University

Heath Park

Cardiff CF14 4XN

UK

Email: AsanatiK@cardiff.ac.uk 


\section{Occupational lung disease; the need for a global surveillance system}

Dear Editor,

We read with great interest the editorial by Reynolds \& Blanc ${ }^{1}$ on "Forging effective surveillance for work-related lung disease". On its 30th anniversary, the authors cleverly looked at initial objectives of Surveillance of Work-related and Occupational Respiratory Disease (SWORD) programme and how these objectives have been met over the last three decades.

There is one point that we would like to add to what Reynolds \& Blanc ${ }^{1}$ wrote about SWORD. This is the potential to globalise the successful SWORD surveillance system for capturing international data with a view to improving the health and well-being of all workers globally. A good indication is the recent epidemic of accelerated stone silicosis, which

Formatted: Highlight $\underline{\text { such a global surveillance system could have detected earlier. }{ }^{2,3}}$

In order to successfully run an international surveillance programme, expertise around the

Formatted: Highlight world in this niche area seems to be essential. In this context, the present studyWeb of Formatted: Highlight Science was performed-searched between 1970 and 2020 with-for the aim of Formatted: Highlight examiningcountry of affiliation of authors of papers on asbestos-related lung disease, occupational asthma, hypersensitivity pneumonitis and silicosis. The following terms were searched: what proportion of publications on topies of asbestos-related lung disease, eccupational asthma and silicosis are contributed by different countries. 
Asbestosis, pulmonary fibrosis - from Asbestos Exposure, Idiopathic Interstitial Pneumonia Asbestosis, pulmonary fibrosis - from Asbestos Exposure, Idiopathic Interstitial Pneumonia -

- Silicosis, anthracosilicosis, silicotuberculosis, progressive massive fibrosis

- Occupational asthma, occupational asthmas, work-related asthma, work-exacerbated asthma, work-aggravated asthma

- Hypersensitivity Pneumonitis, Respiratory Hypersensitivity, Extrinsic Allergic

$\underline{\text { Alveolitis, Extrinsic Allergic Alveolitides, Bird Fancier's Lung, Farmer's Lung, Silo }}$

Filler's Disease, Trichosporonosis

The results show that the G7 countries which are seven largest economies in the world have been the most active countries in producing knowledge in the field of occupational lung disease (the United States, Japan, the United Kingdom, Canada, France, Germany and Italy).

More importantly, figure 1 shows that there are parts of the world, including Africa, the Gulf countries, Eastern Europe and South America with minimum or no activities in occupational $\underline{\text { lung disease publications. These countries are likely to benefit the most from occupational }}$ health input for respiratory disorders.

A minimum activity on producing knowledge about occupational lung diseases in a large proportion of the world is a good indication of a lack of information on occupational lung diseases in those countries. As the global burden of lung disease is not evenly distributed 
between countries ${ }^{4}$ this risks research evidence being of variable validity to the needs of workers in different countries. This may demonstrate the applicability of the "Inverse Care Law" 5 . This is defined as "availability of good medical care tends to vary inversely with the need for it in the population served" 5 .

In order to empower policy-makers to tackle occupational lung diseases globally, there is a need for an international SWORD system to capture data in order to inform policies. A first step to achieve this could be to train professionals in those countries with less activities in this field to have a meaningful input to the international SWORD system. Setting up distance learning courses on occupational lung disease_seems to be an appropriate starting point to reach the final objective of a global SWORD scheme.

\section{References}

1. Reynolds C, Blanc P. Into ploughshares: forging effective surveillance for workrelated lung disease. Occupational and Environmental Medicine. 2019;76(11):783$\underline{784 .}$

2. 2. Leso V, Fontana L, Romano R, Gervetti P, Iavicoli I. Artificial Stone Associated Silicosis: A Systematic Review. International Journal of Environmental Research and Public Health. 2019;16(4):568.

3. Edwards G. Accelerated Silicosis_-An Emerging Epidemic Associated with Engineered Stone. Comment on Leso, V. et al. Artificial Stone Associated Silicosis: 
A Systematic Review. Int. J. Environ. Res. Public Health 2019, 16 (4), 568,

doi:10.3390/ijerph16040568. International Journal of Environmental Research and Public Health. 2019;16(7):1179.

4. Ferkol T, Schraufnagel D. The Global Burden of Respiratory Disease. Annals of the American Thoracic Society. 2014;11(3):404-406.

5. Tudor Hart J. THE INVERSE CARE LAW. The Lancet. 1971;297(7696):405-412. 